\title{
ESCOLARIZAÇÃO, LINGUAGENS E INTERNET, HOJE
}

\section{Marcos Gustavo Richter}

O que significa vivenciar a cultura, a informação e a escolarização hoje, na era da Web? A velocidade do texto cultural da sociedade, isto é, do fluxo diacrônico e sincrônico de textos na semiosfera social, alcança nos dias que correm proporções jamais antes imaginadas. As informações, hoje espantosamente efêmeras, distribuem-se à cognição dos sujeitos por um caleidoscópio de meios e formatos - que acrescentam e subtraem alguma coisa, a seu modo; que competem com uma miríade de textos verbais e não-verbais pela legitimidade em nível do fato, da opinião, da persuasão e da dissuasão; que convivem entre si da maneira mais democrática possível, e isto até numa conotação pejorativa: qualidade e refugo disputando espaços apertados pela percepção dos usuários. Os objetos comunicativos produzidos e à solta passam a assemelhar-se — para empregar uma metáfora oportuna - com o que capta fugazmente, nas palavras de Baudelaire, o pintor da vida (então) moderna: não há quase condições para o encontro face-a-face de signos-transeuntes; aos olhos o que se tem são aparecimentos e desaparecimentos, quase-retratos do cotidiano. Analisar cede lugar a perceber, e à percepção (quase) nada mais resta senão pincelar na tela da mente quase-formas, lampejos de cor-informação. Mas, não nos dias dos impressionistas, e sim nos da virada de milênio, a situação é particularmente séria: não haverá algo urgente a resgatar, ainda que pensando-se dialeticamente, quando o assunto é educar(-se)?

Essa pergunta, se repararmos bem, é particularmente inquietante, na medida em que focaliza uma instituição caracterizada por uma profunda defasagem em relação às práticas sócio-culturais. Certamente não há nenhuma novidade em comentar que a escola cria um espaço artificial em relação à exterioridade, chamada, quem sabe com uma ponta de ironia, de "mundo real". Contudo, é oportuno deter-se no fato de que as novas tecnologias com suas novas relações e funções sociais, suas novas formas de percepção da realidade e seus novos valores e expectativas, tudo isso deita raízes demasiado tardias na instituição escolar formal.

Imagine-se agora uma sala de aula com um(a) professor(a), algum livro-texto, dezenas de alunos militar e assepticamente perfilados nuca-face em suas carteiras, quadro-negro, giz e "saliva". Há quantas gerações esse setting mofa em nossas imaginações? Lá fora, inclusive em suas casas, esses alunos navegam nas redes da Internet pelo mundo todo em seus computadores, mandam e recebem mensagens sem sair de casa, lêem notícias, desfrutam de lazer eletrônico e até mesmo compram pelo cabeamento telefônico (e estamos chegando à Internet sem fio...). Que professor é esse que não sabe o que fazer com crianças e adolescentes que o ultrapassam no know-how de localizar informações? A pretensa "superioridade" deste tipo arcaico de docente — fachada desacreditada, supostamente assegurada no livro impresso usado há décadas e no axioma "Sou professor, portanto sei tudo" — só pode ser pura bravata (artifício 
este, por sinal, inconfessável...).

A respeito deste choque entre arcaísmo e práticas de ponta, escreve Moran (s/d, p.2):

Com a Internet estamos começando a ter que modificar a forma de ensinar e aprender tanto nos cursos presenciais como nos de educação continuada, a distância. Só vale a pena estarmos juntos fisicamente - num curso empresarial ou escolar - quando acontece algo significativo, quando aprendemos mais estando juntos do que pesquisando isoladamente nas nossas casas. Muitas formas de ensinar hoje não se justificam mais. Perdemos tempo demais, aprendemos muito pouco, nos desmotivamos continuamente. Tanto professores como alunos temos a clara sensação de que em muitas aulas convencionais perdemos muito tempo. Podemos modificar a forma de ensinar e de aprender. Um ensinar mais compartilhado.

Para o autor, as novas tecnologias não são uma simples sofisticação, e sim uma resposta às novas necessidades educacionais surgidas (op.cit, p.2):

Ensinar e aprender exigem hoje muito mais flexibilidade espaço-temporal, pessoal e de grupo, menos conteúdos fixos e processos mais abertos de pesquisa e de comunicação. Uma das dificuldades atuais é conciliar a extensão da informação, a variedade das fontes de acesso, com o aprofundamento da sua compreensão, em espaços menos rígidos, menos engessados. Temos informações demais e dificuldade em escolher quais são significativas para nós e conseguir integrá-las dentro da nossa mente e da nossa vida. A aquisição da informação, dos dados dependerá cada vez menos do professor.(...) O papel do professor - o papel principal - é ajudar o aluno a interpretar esses dados, a relacioná-los, a contextualizá-los.

Portanto, segundo o autor, a escola dispõe, hoje (embora ainda para uma minoria), de meios para assimilar a transversalidade da informação, via novas tecnologias. Porém a manutenção de uma das grandes tarefas formativas da escola, a integração dessas informações na forma de legítimo conhecimento (decorrente do exercício da reflexividade crítica) ainda é uma indagação provocativa para os investigadores da área, haja vista a experiência infeliz que tivemos recentemente com a pretensa "modernização" do ensino: os órgãos governamentais despejaram verdadeiras enxurradas de aparelhos de tevê e vídeocassete em nossas escolas, como se a mera presença destes pudesse automaticamente alterar as relações educador-educando. Faltou o mais importante: apoio aos docentes para que soubessem assimilar as novas tecnologias, quer em sua formação teórica, quer em suas práticas de sala de aula. $E$ hoje muitas dessas escolas amontoam equipamento sucateado em algum canto - enquanto que nas classes os professores amontoam práticas educativas sucateadas.

Urge, claramente, fazer o que Umberto Eco já sugeria em sua conferência From Internet to Gutemberg:

"Estamos hoje desaparelhados para discriminar, ao menos num primeiro momento, entre uma fonte confiável e uma ruim. Precisamos de uma nova forma de competência crítica, uma ainda desconhecida arte de seleção e 
descarte de informação, em suma, uma nova arte de julgar. Precisamos de um novo tipo de treinamento educativo." (Eco, 1996: não paginado)

Eco adverte que a imagem em si mesma comporta um tipo de retórica capaz de induzir o receptor a cair em falácias argumentativas, dada a sua predisposição a gerar idéias falsamente generalizantes. Ou seja, ela leva o interpretante do usuário desavisado a converter impropriamente um fenômeno particular, com suas especificidades contextuais e sua probabilidade intrinsecamente baixa, em normas ou expectativas gerais e, portanto, manifestações típicas e prováveis da realidade. Por essa razão, diz o semioticista, ela deve ser estrategicamente contrabalançada com a linguagem verbal.

O autor assinala, além disso, que a competência hipertextual, a qual habilita o leitor-navegador a inventar novos textos ou novas colagens e bricolagens verbovisuais, vivenciar a experiência do "texto infinito" (ou da obra radicalmente aberta), cancelar ou pôr em xeque o conceito de autoria e a oposição autor-leitor, também leva aquele a uma nova situação-limite: a saber, como administrar o excesso de informação, decantando o relevante do oceano de irrelevâncias da Web, segundo os propósitos do usuário?

De nossa parte, cremos que a capacidade de escolha e discriminação (o planejarreplanejar, o planejar-em-desenvolvimento) faz parte da dimensão terceira da relação homem-signo no mundo pós-moderno, enquanto que a abertura às possibilidades, a singularidade de cada leitura estabelece a contraparte dialética da semiose na primeiridade que confere a pregnância à terceiridade, permitindo que essa leitura-ação aponte para um horizonte interpretativo sempre renovado (o interpretante final assintótico), (re)direcionando para isso constantemente a conduta no sentido da rede de causalidades eficientes (a fúria ativo-reativa da percepção na relação olho-tela) e conferindo um sentimento de razoabilidade ao que está procedendo, entendido como qualidade estética. Vale dizer, impregnando a semiose hipertextual de "um sentimento que é a Impressão de uma Razoabilidade que Cria. É uma primeiridade que realmente pertence à Terceiridade na sua realização da Secundidade" (Peirce, apud Santaella, 1992:181).

Porém, mais uma vez remetendo ao paradigma vygotskiano (Vygotsky, 1994, 1995, 1998; Oliveira,1995), lembramos que o cérebro humano, em sua plasticidade inerente, não está predisposto a esse desempenho cognitivo, muito menos ao seu uso criticamente direcionado, exceto após ser pacientemente forjado como resultado da internalização de práticas sociais intersubjetivas conduzidas de maneira adequada e monitoradas por sujeitos (mais) competentes e responsáveis. Estamos nos referindo, mais precisamente, à relação educadoreducando. Daí que o primeiro deverá desenvolver em si mesmo as mesmas competências hipertextuais que deseja ver bem empregadas no segundo, em contextos cooperativos: o processo educativo deve desenvolver-se na Zona de Desenvolvimento Proximal para frutificar, de forma que o aprendizado "puxe" para cima o desenvolvimento.

Eco faz, nesse mesmo texto, uma distinção entre livros para simples informações 
ou então consultas - seriam aqueles que poderiam abandonar com proveito a forma impressa e circularem na forma digital, como obras de consulta, enciclopédias, material jornalístico, etc. - e livros impressos, para reflexão. Aqueles seriam livros "abertos", aptos para a construção singular de sentidos no pleno exercício da Liberdade; estes, livros "fechados", no sentido de que o leitor vivenciaria o lado mais injuntivo da vida (e da morte), a Lei da Necessidade. O semioticista italiano não menciona, na conferência, a que veio essa sua preocupação com a "Lei da Necessidade"; mas nos aventuramos a justificar, à revelia do autor, o levantamento dessa questão. Zizek (1992), escudado na literatura freudiano-lacaniana, mostra que o superego pós-moderno está estruturado num lugar pré-edipiano, imaginariamente avesso à castração; portanto, avesso à incidência da Lei (o Nome-do-Pai) sobre seu desejo, limitandoo. Ora, denegar o determinismo da vida e da morte é, de certa forma, denegar a existência das gerações na vida humana e, algo sutilmente, pôr em xeque a interdição do incesto. Claro que a existência, na cultura, da leitura-semiose determinística (ocupando um lugar ao lado da outra, bem entendido) pode contribuir decisivamente para arrefecer o ímpeto perverso de limitar-se a construir sentidos ad libitum, ao custo (proveitoso só para os formadores da macropolítica psicológica) — este, sim, bem lembrado por Eco — de isolar o sujeito na massa.

Porém, a rigor, não compartilhamos do tom algo fatalístico do semioticista italiano quando este adverte para os perigos de não reservar o devido lugar ao livro "acabado" e impresso. Isto, porque, dialeticamente falando, não só o livro impresso mas também tudo o que veio antes dele na história da cultura humana não fica relegado ao ostracismo. Apenas muda o lugar antes ocupado por esses artefatos: muda sua funcionalidade, alteram-se suas formas e momentos de aparição. Historicamente, inclusive, isso ocorreu até mesmo com o livro de papel. Inicialmente, ele era lido em voz alta por alguém, enquanto, em intervalos, paravase para discutir oralmente o que o livro propunha. Posteriormente, o lugar do livro alterou-se. Como na passagem dos eventos sociais da praça pública para os recantos privados da habitação burguesa, ele se torna sinônimo de apropriação solitária e silenciosa. A "solidão" do micreiro que passa horas na Internet estará, porventura, muito distante daquela do leitor de livros "acabados"? Este ponto merece ser examinado com mais calma. Mas não é nosso objetivo fazê-lo aqui.

$\mathrm{Na}$ verdade, deslizaremos para outro aspecto do debate, relacionado com o novo tipo de racionalidade que permeia e guia o próprio ato de ler. Pois o lugar do livro é, hoje, outro, também porque o ato de ler mudou. Senão vejamos. Xavier (s/d) assinala que uma forma de leitura precursora da hipertextual já existia antes da era digital, na forma das múltiplas formas remissivas do material impresso, livro ou jornal (notas de rodapé ou de final de capítulo, sumários, os "vide página..." ou "leia mais na página/caderno..."), mas a quebra da linearidade, a ausência de foco dominante de leitura passou a ser princípio básico da concepção/construção dos textos.

Não se trata de encarar um texto eletrônico como uma figura caleidoscopicamente mutável, e sim como um campo plural de textos dotados de um grau básico de linearidade (típica do processamento verbal: linear, analítico, em série). Perguntamos, então: que tipo de pluralidade está implicado? Resposta: uma 
pluritextualidade - cuja função é dissolver as fronteiras que inibem a interdisciplinaridade. E continuamos perguntando: se no passado a lógica logocêntrica do livro impresso já abrigava remissões, "pulos" na leitura serial, que mudança ocorreu, que pode ser considerada cognitivamente relevante? Resposta: a emergência da lógica da transição - que é a lógica da transversalidade.

Welsch (apud Sandbothe,1996), após definir a razão como a faculdade cuja tarefa é refletir sobre a relação entre diversos tipos de racionalidade, traça o seguinte perfil para a razão transversal:

1. Reconhece-se que a constituição da racionalidade é inseparável de uma inelutável desordem - asserção esta que contraria a idéia segundo a qual a razão relaciona-se com a estruturação de racionalidades claramente separadas umas das outras. Na Web, particularmente, torna-se explícito o fenômeno da desordem da racionalidade. Welsch (op. cit.: 15) mostra que

\footnotetext{
"a ordenada clássica estrutura racional de conhecimento, estética e moral prática é um fenômeno superficial. Uma contingente rede de 'parentescos de família' entre diferentes paradigmas e alianças de paradigmas formam seu fundamento. A máxima da teoria da racionalidade resulta dessa afirmação: 'O todo do sistema de circulação horizontal e vertical se recobrem (sic) (...) entrelaçamentos interparadigmáticos são, na sua maior parte, não hierarquicamente, mas lateralmente organizados. A conexão tem mais a estrutura de uma rede do que de estratificação."
}

Vale dizer: se, por um lado, o livro impresso ("fechado") e o pensamento acadêmico mais ocultam do que explicitam os emaranhados e transições das racionalidades - a cognitiva (via da informação e comércio), a moral prática (via da educação) e a estética (via do entretenimento) - , a Web, por outro lado, coloca-os às claras, na medida em que essas distinções são introduzidas pelos receptores em uma estrutura complexa de hiperlinks cujos parentescos de família internos alteram-se e reconfiguram-se constantemente conforme as diferentes perspectivas dos mesmos usuários. A constituição mesma das racionalidades passa a apresentar analogia com o movimento e a mudança.

2. A razão passa a operar como uma metafaculdade capaz de justamente reconstruir e descrever essa desordem - o que consideraríamos como um antídoto contra os riscos e ingenuidades das posições de arbitrariedade e displicência no campo do pensamento contemporâneo. O modus operandi da razão transversal vai abandonando a rígida dicotomização das coisas em certo/errado, tudo/nada, em favor do mais/menos, ou também segundo a lógica do "trans". Não há mais um "centro irradiador" do exercício da racionalidade, e sim constelações de nós paradigmáticos que lateralmente dialogam entre si ao manifestar sempre "a outra perspectiva". Mas esta relativização, por sua vez, está acompanhada da "leitura ao avesso", ou seja, "a outra perspectiva" existe porque virtualmente sempre se pode lançar, e dar resposta, a uma questão: "e se as práticas assim manifestas estivessem invertidas quanto a agentes, contextos, propósitos, qual seria a racionalidade 'apagada', recalcada, por trás disso?" Ora, o resultado desse processo é o exercício do desvelamento da realidade ex-centrada 
de qualquer paradigma. Por sua vez, o apelo à dimensão prática da realidade para sua interpretação nos leva à terceira característica:

3. A razão transversal opõe-se à formulação de problemas como decorrência da mera aplicação de modelos abstratos da realidade. Responde a isso procurando refletir transversal e pragmaticamente sobre "aquelas constelações de racionalidade que são práticas efetivas e que já estão determinadas no seu interior por realidades contingentes." (op. cit.: 15) A transversalidade, portanto, está presente lá onde se desenvolve um trabalho reflexivo de sujeitos voltados a indagações sobre suas próprias práticas, ao mesmo tempo que, dada a primazia do icônico sobre o verbal-serial e a horizontalidade dos paradigmas (no ciberespaço), essas indagações demandam a habilidade da decifraçãoreconstrução (dos sentidos), ainda por vir.

Não é difícil concluir que a transversalidade será constitutiva do educador da era digital. Portanto, faz parte do modelo de docente que podemos (e devemos) construir em nosso horizonte utópico e está, portanto, pressuposto neste ensaio. Se agora o leitor se pergunta: quais são os caminhos viáveis para a construção dessa transversalidade na relação intersubjetiva educador-educando - falo agora mais de perto ao professor de línguas e/ou outras linguagens - , respondo que esta é a questão que lhe deixo e proponho para futuros debates e reflexões.

\section{BIBLIOGRAFIA:}

BACHA, MARIA DE LOURDES. A teoria da investigação de C. S. Peirce. São Paulo: PUC-SP, 1997. Dissertação de mestrado.

BAUDRILLARD, JEAN. "Significação da publicidade". In: LIMA, LUIZ C. (org.)

Teoria da cultura de massa. Rio de Janeiro: Paz e Terra, 1982.

CARR, WILFRED; KEMMIS, STEPHEN. Becoming Critical. Deakin University Press, 1986.

De MASI, DOMENICO. O ócio criativo. Rio de Janeiro: Sextante, 2000.

ECO. UMBERTO. From Internet to Gutemberg. http://www.italynet.com/columbia/internet.html, 1996.

FRANCO, MARCELO ARAÚJO. "Linguagens, Comunicação e Cibercultura: novas formas de produção do saber". In: Revista Informática na Educação 05, junho 1999. http://www.revista.unicamp.br/infotec/educacao/educacao5-1.html.

KEMMIS, STEPHEN; CARR, WILFRED. Teoria crítica de la enseňanza. Barcelona: Martinez Roca, 1988.

KEMMIS, STEPHEN; McTAGGART, ROBIN. Como planificar la Investigación-Acción. Barcelona: Laertes, 1988.

MORAN, JOSÉ M. Mudar a forma de ensinar e aprender com tecnologias. s/d. http://www.eca.usp.br/prof/moran/uber.htm

NUNAN, DAVID. Course design. Oxford: Oxford University Press, 1994.

OLIVEIRA, MARTA K. de. Vygotsky. Aprendizado e desenvolvimento: um processo sócio-histórico. São Paulo: Scipione, 1995.

PAZUKHIN, ROSTISLAV. " A contribution to the general theory of models". In: Semiotica $67-1 / 2,61-82$.

PEIRCE, CHARLES SANDERS. Semiótica. São Paulo, Perspectiva, 1977.

PEREIRA, MARIA A.; SOARES, HOLGONSI. O sentido da autonomia no 
processo de globalização. Santa Maria, s/d, inédito.

RICHTER, MARCOS G. Ensino do português e interatividade. Santa Maria: Editora UFSM, 2000.

SANDBOTHE, MIKE. "Interatividade, hipertextualidade, transversalidade: uma análise da Internet a partir de uma filosofia da mídia". In: Caderno de Filosofia e Ciências Humanas. Faculdades Integradas Newton Paiva. Ano IV, No 7, Outubro 1996, p.5-17.

SANTAELLA, LÚCIA. A assinatura das coisas: Peirce e a Literatura. Rio de Janeiro: Imago, 1992.

SANTAELLA, LÚCIA. A teoria geral dos signos: semiose e autogeração. São Paulo:Ática, 1995.

SANTAELLA, LÚCIA; NÖTH, WINFRIED. Imagem: cognição, semiótica, mídia. São Paulo: Iluminuras, 1998.

SARDAR, ZIAUDDIN; Van LOON, BORIN. Introducing Cultural Studies. Nova York: Totem Books, 1998.

VYGOTSKY, LEV S. A formação social da mente. São Paulo: Martins Fontes, 1994.

VYGOTSKY, LEV S. Obras escogidas V. III. Moscou: Editorial Pedagógica, 1995.

VYGOTSKY, LEV S. Pensamento e Linguagem. São Paulo: Martins Fontes, 1998.

XAVIER, ANTONIO CARLOS S. Leitura, texto e hipertexto. s/d. http://www.unicamp.br/ hytex/artigo.htm

ZIZEK, SLAVOJ. Eles não sabem o que fazem: o sublime objeto da ideologia. Rio de Janeiro: Jorge Zahar, 1992. 